\title{
BMJ Open Exploring the perceptions and barriers of nurses working in remote areas on tele-educational delivery of pharmacy knowledge in Henan, China: a qualitative study
}

Wan Zhang, Xuedong Jia, Xiali Yao, Xiang Zhang, Yan Liang, Yingjie Zhang, Xiao Zhang, Pei Su, Xiaojian Zhang, Shuzhang Du, Zhao Yin

To cite: Zhang W, Jia X, Yao $\mathrm{X}$, et al. Exploring the perceptions and barriers of nurses working in remote areas on tele-educational delivery of pharmacy knowledge in Henan, China: a qualitative study. BMJ Open 2022;12:e051365. doi:10.1136/ bmjopen-2021-051365

- Prepublication history for this paper is available online. To view these files, please visit the journal online (http://dx.doi. org/10.1136/bmjopen-2021051365).

Received 17 March 2021 Accepted 10 January 2022

Check for updates

(c) Author(s) (or their employer(s)) 2022. Re-use permitted under CC BY-NC. No commercial re-use. See rights and permissions. Published by BMJ.

Department of Pharmacy, Zhengzhou University First Affiliated Hospital, Zhengzhou, Henan, China

Correspondence to

Mr Zhao Yin;

yinzha00601@163.com

\section{ABSTRACT}

Objective There are insufficient educational resources and opportunities available to nurses at county-level medical institutions in China to receive pharmacy knowledge education. Video conference pharmacy education (VCPE) has become a solution. However, a few studies have explored the perceptions of nurses participating in VCPE. The study was aimed to explore the perceptions of nurses participating in VCPE at county-level medical institutions in remote areas in China. The barriers and suggestions to improve the VCPE were also assessed. Setting The study was conducted in two county-level hospitals in Henan, China.

Design and participants This qualitative study comprises two focus group discussions. Twenty-three nurses from two county-level hospitals in Henan province participated in the interview in May 2019.

Results The average age of our participants was $34.83 \pm 6.24$ years old (from 26 to 55 years old). By deeply analysing the data, the following four domains were extracted: Four themes were extracted on VCPE from this qualitative study: (1) the pharmacy knowledge gains from VCPE, (2) the shortcomings VCPE, (3) the advantages of the VCPE and (4) the expectations and suggestions for the VCPE.

Conclusion The results of this study indicate VCPE is a valuable tool to provide education to nurses working at remote area county-level institutions. The results contribute to improvements in future VCPE deliveries.

\section{INTRODUCTION}

In China, clinical pharmacy services provided at hospital settings only started in the early 1990 s $^{1}$ resulting in a shortage of clinical pharmacists and poor pharmacy support for nurses or other medical stuff at remote county-level medical institutions. ${ }^{23}$ Studies have indicated that nursing staff, working at these medical institutions, need to receive pharmacy training to care for patients. ${ }^{4}$ Pharmacology education generally includes (1) drug information, such as preparation, administration and storage; (2)

\section{Strengths and limitations of this study}

- This is the first qualitative study in Mainland China to explore the experience and expectations of nurses participating in remote pharmacy knowledge training.

- The present relies on in-depth group discussions and interviews, providing rich data on the experiences of participants.

- The research subjects only included nursing staff from two hospitals in Henan Province, which has certain limitations.

- Another limitation includes potential for sexual bias since all of the participants are females.

basic knowledge of pharmacotherapy, chronopharmacology and pharmacokinetics; (3) ability to monitor drug efficacy and adverse drug reaction and (4) appropriate drug use in pregnant patients, elderly patients and paediatric patients. ${ }^{5}$ However, due to the remote location, nurses are struggling to get educational resources and opportunities at the places they work. Traditionally, they have to attend in-person classroom learning or conferences hosted at larger cities, ${ }^{6}$ which requires an expense of time and money. Using information technology and video conferencing capabilities, tele-education has been explored to solve this problem. ${ }^{7}$ Compared with the traditional model, video conference training is efficient, saving both time and money. ${ }^{8}$ Under this new model, close cooperation and alliance relationships between county-level and higher-level medical institutions can be established. With video conference learning, learners have the option to attend real-time or conduct home study through watching recorded lectures. Despite these advantages, a lack of classroom 
interaction and absence of a strong learning atmosphere have been noted in video conference learning. ${ }^{8}$

Although telemedicine in China started relatively late, originated in the mid-1980s, it has developed rapidly. ${ }^{9}$ At present, 'video conference' has become a common means of continuing education for remote county-level nurses in China. ${ }^{9}$ As one of the largest hospitals in China and the world, the First Affiliated Hospital of Zhengzhou University has established the National Telemedicine Center. The hospital pharmacists have been conducting video conference pharmacy education (VCPE) for nurses from more than 200 county-level medical institutions through this telemedicine centre since 1996. With this VCPE platform, pharmacists can provide continuing education in pharmacy knowledge for nursing staff working in remote areas. ${ }^{10}$ To assess the perceptions and learning experience of the county-level nursing staff participating in the VCPE and better evaluate programme outcomes, it is necessary to conduct qualitative studies. The aim of this qualitative study was to gain knowledge about the perceptions and expectations of county-level nursing staff (learners) in remote areas towards the VCPE delivery.

\section{METHODS}

Giving that the aim of this study was to describe the perceptions of nurses participating in VCPE at countylevel hospitals in remote areas in China, a qualitative descriptive approach was used (Sandelowski, 2000). Reporting was based on the Consolidated Criteria for Reporting Qualitative Health Research guidelines.

\section{Study design}

A research team was established comprised of two education experts, three pharmacists and a management expert. Among them, education experts are mainly involved in the design of research plans and the formulation of interview guide. The three pharmacists are mainly responsible for the design of the research plan, the implementation of focus group interviews, data analysing and manuscript writing. The management expert is mainly responsible for methodological guidance and quality control. All members had experience conducting qualitative studies. Based on literature review, personal experience and opinions, the multidisciplinary team developed a semistructured interview guide. Preinterviews were performed, and revision was made to optimise the interview guide. The final version of the interview guide included three main questions: (1) Please share your real experience of participating in this VCPE; (2) Please share your expectations for VCPE in the future and (3) What are your suggestions on the content, format, training personnel or time arrangement of VCPE.

VCPE is developed with the support of the videoeducation platform of the National Telemedicine Centre. County-level hospitals participating in the project have established close network connections with provincial hospitals such as the First Affiliated Hospital of
Zhengzhou University. In this project, the main teaching unit is the department of pharmacy of the First Affiliated Hospital of Zhengzhou University, and the teachers are generally experienced clinical pharmacists or dispensing pharmacists. Online classes are arranged twice a month, usually at 3:00 pm on Mondays in the first or third week. Each lesson lasts about $50 \mathrm{~min}$. The teaching syllabus is prepared in advance every year, and the courseware is reviewed by a pharmacy expert group, and the teaching can be carried out after passing. The main content of the course includes the daily management of drugs, the rational use of antibacterial drugs, the management and rational use of opiates or psychotropic substances, medication therapy management for chronic diseases, pharmacoeconomics and so on. Before each online class, a manager in charge of the telemedicine centre publishes the teaching content on the platform, and lower-level hospitals can freely choose. The lower-level hospitals then organise their medical staff to study through video and evaluate them accordingly. We conducted two focus groups at a time convenient for the participants in May 2019 with participants having completed at least one VCPE course. All interviews were digitally recorded with the permission of the participants and then transcribed verbatim. Two interviewers reviewed the transcripts to guarantee accuracy. All original recordings and transcriptions were in Chinese and were translated into English then back-translated into Chinese to ensure the translation consistency. Transcripts were managed using the NVIVO V.12 software (QSR International, Melbourne, VIC).

\section{Recruitment}

Participants were selected from two county-level hospitals in Henan, Central China. Those two hospitals are located in remote areas of Henan province, and the nearest large provincial hospitals are more than $200 \mathrm{~km}$ away. In addition, according to previous records, the two hospitals have a relatively high enthusiasm for participating in VCPE. The inclusion criteria of the research subjects are as follows: (1) Nurses who formally work in these two hospitals; (2) Finished at least one complete VCPE course and (3) Willing to participate in this study. Purposeful sampling and snowball sampling strategies were used to recruit volunteers. Before the interview, the research team communicated with the potential participants of the two hospitals in advance to determine the time and place to participate in the interview. Twenty-three participants were included in the study until data saturation was achieved. Written informed consents were then obtained from all participants prior to study start. The demographic information of the participants was collected.

\section{Data analysis}

Data were analysed by the Haase's adaptation of Colaizzi's phenomenological method, ${ }^{11}$ shown as figure 1 . The code of each participant consists of the corresponding group number and participant number. For example, 'G1P1' represents the 
1.Transcribing all the subjects' descriptions

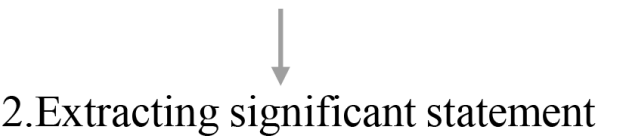

3.Creating formulated meanings<smiles>[C]1C=C1</smiles>

4.Building themes

5.Developing an exhaustive description

6.Identifying the fundamental structure of the phenomenon

\section{Returning to participants for validation}

Figure 1 The whole step of Colaizzi's phenomenological method.

first participant in the first group. Two team members analysed the transcripts independently followed by the research team conducting thematic analysis and comparing findings. Themes, theme clusters and representative statements were developed until consensus was achieved. Guidelines were applied to guarantee dependability, transferability, confirmability and credibility of our study.

\section{Trustworthy}

To maintain trustworthiness, the following was taken into consideration: (1) investigators communicated frequently with guidance experts, (2) interview data were returned to participants to confirm that the investigator's understanding coincided with the meaning the participants wanted to express and (3) guidance of conducting qualitative study were strictly followed during researching.

\section{Patient and public involvement}

Patients and the public were not involved in this research initiative.

\section{RESULTS}

Twenty-three nurses (all were females) were enrolled in this study, with an average age of $34.83 \pm 6.24$ years old (from 26 to 55 years old). Their average time to participate in nursing work was $11.13 \pm 7.26$ years. These participants were enrolled from multiple departments, which included intensive care unit (ICU) (six), rehabilitation (four), surgery (four), neurology (two), administration (two), internal medicine (one), cardiology (one), ophthalmology (one) and neurosurgery (one). The demographics of participants are shown as table 1. By deeply analysing the data, the following four domains were extracted: (1) the pharmacy knowledge gains from VCPE, (2) the shortcomings VCPE, (3) the advantages of the VCPE and (4) the expectations and suggestions for the VCPE (figure 2).

\section{Domain 1: the pharmacy knowledge gains of nursing staff from county-level medical institutions participating in the VCPE}

The biggest gain reported by participants was the learning of new clinical knowledge and practice pearls.

I come from the First Department of Cardiovascular Internal Medicine. I think. routine nursing care pays more attention to treatment. After listening to this nutritional knowledge today, I have improved my knowledge of patient care (G1P1)

There is a detailed introduction in today's course. For example, when the injection. volume is less than 500 $\mathrm{mL}$ every 6 hours, we can continue to use this nutrient pump, to which we did not pay attention before; and there are some tips like headboard elevation (G2P4)

Due to lack of timely continuing education about pharmacology, participants had misconceptions that needed to be addressed to improve the delivery of care. The VCPE addressed details in patient care, such as the weight loss of patients after surgery, and nutritional problems found in patients who were bedridden for a long time. After participating in the training, these misconceptions were corrected.

I am a surgical nurse. I used to think that it is normal for patients to lose weight. after surgery. After listening to the lecture, I understood that this is because the nutrition after surgery has not kept up. This is a new understanding. In addition, what the teacher said is (laughs) that simply supplementing patients with amino acids or fat emulsions is a waste of resources and is unscientific if not combined with other nutrients, which is also not comprehensive (G2P3).

For the most part, speakers from higher-level medical institutions were able to share more up to date knowledge through video conferences for county-level nursing staff. The knowledge gained broadened nurses' professional horizon and stimulated their interest and motivation to further learn related knowledge.

At the beginning, I didn't have a comprehensive understanding of the content of this. course, and then through video learning, I got motivated to understand it more deeply and master some basic knowledge (G1P12)

Teaching some cutting-edge knowledge can broaden our horizons. However, maybe. we don't have so much time to learn by ourselves. We are busy at work and we have to take care of the children. Through tele-education, we are opening up some new horizons and see some new knowledge (G1P11). 
Table 1 The demographics of participants $(n=23)$

\begin{tabular}{|c|c|c|c|c|}
\hline No & Title & Familiarity with VCPE & Expectation of VCPE & $\begin{array}{l}\text { Times of participations in } \\
\text { VCPE }\end{array}$ \\
\hline G1P1 & Primary nurse & 2 & 5 & 3 \\
\hline G1P2 & Nurse & 5 & 4 & 10 \\
\hline G1P3 & Primary nurse & 3 & 4 & 4 \\
\hline G1P4 & Primary nurse & 5 & 5 & 1 \\
\hline G1P5 & Nurse & 5 & 5 & $>10$ \\
\hline G1P7 & Senior nurse & 5 & 5 & 2 \\
\hline G1P8 & Nurse & 3 & 5 & 3 \\
\hline G1P9 & Primary nurse & 5 & 5 & $>10$ \\
\hline G1P10 & Primary nurse & 3 & 4 & 5 \\
\hline G2P2 & Primary nurse & 3 & 4 & 1 \\
\hline G2P3 & Nurse & 3 & 4 & 1 \\
\hline G2P4 & Nurse & 3 & 5 & 1 \\
\hline G2P5 & Nurse & 3 & 5 & 1 \\
\hline G2P6 & Primary nurse & 2 & 5 & 1 \\
\hline G2P7 & Nurse & 2 & 5 & 1 \\
\hline G2P8 & Nurse & 3 & 5 & 1 \\
\hline G2P9 & Nurse & 2 & 3 & 1 \\
\hline G2P10 & Nurse & 2 & 5 & 1 \\
\hline
\end{tabular}

Familiarity with VCPE (very familiar, 5; familiar, 4; generally familiar, 3; not familiar, 2; not at all, 1); Expectation of VCPE (very expected, 5; expected, 4; generally expected, 3; not expected, 2; not at all, 1).

VCPE, video conference pharmacy education.

\section{Domain 2: the shortcomings VCPE}

Most participants mentioned that improvements were needed in the VCPE model. The main problem identified by participants was that course content was difficult to understand, especially when they encountered relatively abstract medical indicators, English expressions or relatively esoteric content.

I learned which indicators were used to judge the patient's nutritional status, but. some specific indicators mentioned by the teacher were not easily understood (G2P12)

Many of the guidelines we talked about are in English. The English of our county- level staff is not good, so it is best to translate it into Chinese. Our English level is really not good enough to understand the contents (G1P9)

I cannot understand some of the courses. What I heard the most difficult was a. medical course about

\begin{tabular}{|c|c|c|c|}
\hline $\begin{array}{l}\text { The pharmacy } \\
\text { knowledge gains }\end{array}$ & $\begin{array}{l}\text { Areas of improve } \\
\text {-ment needed }\end{array}$ & Advantages & $\begin{array}{l}\text { Expectations } \\
\text { \& suggestions }\end{array}$ \\
\hline $\begin{array}{l}\text { Learning of clinical know } \\
\text {-ledge \& practice pearls } \\
\text { Correcting misconceptions } \\
\text { Broadened nurses' } \\
\text { professional horizon }\end{array}$ & $\begin{array}{l}\text { Difficult to understand } \\
\text { Lack of interaction } \\
\text { Inadequate courses } \\
\text { Lack of learning atmosphere }\end{array}$ & $\begin{array}{l}\text { Convenience } \\
\text { Time \& costs saving } \\
\text { Learn together }\end{array}$ & $\begin{array}{l}\text { Teaching content } \\
\text { Courseware style } \\
\text { Time arrangement } \\
\text { Teaching style } \\
\end{array}$ \\
\hline
\end{tabular}

Figure 2 The framework of domains. 
an ECG. Because our hospital carried out projects involving stroke and myocardial infarction, but I didn't understand the ECG course at all (G1P4)

I tried hard to understand but still couldn't understand, and there was no chance to. solve the doubts in my mind in time (G1P9)

Another problem participants noted was about the interaction during lectures. If instructors did not engage in interaction during lectures, the classroom atmosphere appeared to be boring and listeners would have difficulty in understanding the content.

If the interaction of his video is not good, it will be difficult to understand even though everyone is very interested, the effect will not be good (G1P8)

Some questions that were not understood at the time were not asked at the time, and it would be boring without interaction (G1P12)

Both professional content and clinical content were provided during lectures with a focus on the clinical content. Participants indicated that even though the clinical knowledge had a certain relevance to patient care, overall, there were inadequate courses for nurses.

Basically everyone can understand nursing classes, but there are relatively few nursing classes. There may be only one class for nursing a month, and sometimes there may be no class for nursing in a whole month (G1P6)

Under the traditional face-to-face classroom learning model, learners can be more engaged in the content and tend to be more attentive. These factors create an atmosphere conducive to learning. Compared with this, the VCPE delivery lacked a strong learning atmosphere to engage the learner.

Compared with studying in the classroom, the biggest disadvantage of this way of learning is that there is no atmosphere (G2P8)

\section{Domain 3: advantages of the VCPE delivery}

Participants emphasised the advantages of the VCPE delivery. The main advantage was convenience, which allowed them to choose the time and the content of study.

This is a selective learning. For example, if I take a break today, I will come to listen the lecture if I have time. If I have work, I will not come. With this frequency, I think it's good, because every day someone will work and someone will rest, and if they are free, they will come (G1P7)

The advantage is that our hospital is now free to choose courses. According to your own time, you can come to listen the lecture you choose if you have time. In every department, there are some nurses not on their duties. According to your own time, you can listen to it even if you are not in this department (G1P3)

Participating in VCPE does not require distant travels, which significantly saves related travel time and costs.

This method does not require you to go to the provincial capital or other big. cities, I can learn it in my own unit. This saves money and time. In the past, it took several days to study in other places. In fact, it would cost a lot of money on travel and accommodation (G2P3)

Participants emphasised the importance of learning atmosphere and the learning environment. Some interviewees mentioned that compared with traditional classroom-based learning, the learning atmosphere of VCPE was not strong enough. However, compared with independent online class learning, the learning atmosphere of the VCPE delivery was better.

Compared with learning online classes alone, this is a better learning atmosphere. If there is a learning atmosphere, everyone wants to learn (G1P4)

Ten people are sitting there, nine of them are studying, and the other one who does not want to learn will also start to learn, he will be infected by this atmosphere (G1P8)

\section{Domain 4: the expectations and suggestions for the VCPE delivery}

Participants talked about the learning gains, existing problems, and advantages. On this basis, they put forward specific expectations and suggestions for VCPE delivery. In terms of teaching content, participants mentioned that they hoped to learn pharmaceutical knowledge related to drug infusion, preparation, administration and preservation in future continuing education.

Some drugs have a special order (during infusion), but for most departments, it seems no difference in which bottle to infuse first and which bottle to infuse later, I don't quite understand (G2P12)

The aciclovir that we used some time ago is quite special. Our doctor's order was to add two vials of medicines to $100 \mathrm{ml}$ of saline, but after two vials of medicines were added, it was impossible to drip, the tube would be blocked and you have to stop dripping (laughs). I really want to know why this happens (G2P9)

Our doubt is that some drugs are enteric-coated or slow-released. If we dissolve or crush them, will their effectiveness be affected? (G2P12)

For teaching content, participants would like to learn about the appropriate use of medications in special populations.

Especially for pregnant women, sometimes what kind of medicine can be taken when they have a fever. When they are particularly uncomfortable, can they 
take some antibiotics, can they take cold medicines, and which ones can be taken (G1P4)

Regarding courseware style, participants mentioned that they hoped that teachers would use actual cases with pictures and texts, and each lecture would not contain too much content.

It is better to combine with examples, which will impress us deeper. When referring to a case, the lecturer should talk about what was the situation when the patient came, what was used on the first day, just fat emulsion or just amino acids, or two-in-one or threein-one combination, what was the patient like when they came, and what would happen to them after a week or five days (G1P9)

The lecturer had better not talk too much at a time, because listeners cannot remember too much at a time. The lecturer can talk about a few typical cases at a time, and everyone may understand better (G1P6)

There are some theoretical knowledge in pharmacy, which is difficult to grasp. The lecturer had better add a case or picture, which may be more vivid with pictures and texts (G2P9)

For nurses to better plan their study, interviewees hoped that teachers would communicate learning contents with them in advance.

If you want to make everyone understand the nursing, you should communicate with the nursing staff in advance. In this way, the lessons you teach may be more acceptable to us (G1P8)

Another interviewee mentioned that she hoped the lecture content was recorded in the form of videos and stored on the VCPE platform. This would allow nurses to review the video after attending the VCPE sessions.

Is there that kind of form? Provide us a platform on which we can record courses and click on them anytime after class. In this way, we can learn at home without being restricted by time, place and personnel (G2P10)

Most interviewees thought that a lecture with a duration of 30 minutes to 40 minutes was more appropriate.

If the time can be controlled within $30-40 \mathrm{~min}$, we think it would be more appropriate. Although the content will be less, we think we can absorb it better after listening (G1P11)

Finally, concerning teaching style, participants expected teachers to be passionate and create a good learning atmosphere through interactive methods.

We hope the teacher to be a little bit passionate during the lecture, which can arouse everyone's enthusiasm and enliven the atmosphere (G2P7).

\section{DISCUSSION}

The research team believes this initiative to be the first qualitative study conducted to obtain an understanding of the acceptability of receiving pharmacy education through video conferencing from the perspective of nurses in China. Study results found that the main gains for nursing staff at county-level medical institutions, who attended VCPE sessions, were learning new clinical knowledge and practice pearls. The perceptions, expectations and suggestions of improvement provide a valuable reference to conduct similar continuing education activities in the future.

As identified in this study, nursing staff can complete continuing education that effectively addresses knowledge gaps and patient care misconceptions through participating in VCPE. ${ }^{12}$ This further inspires their learning motivation. ${ }^{12}$ Compared with higher-level hospitals, such as provincial hospitals with higher degrees of specialisation, the working environment for county-level nurses is more complex requiring more comprehensive mastering of knowledge. These nurses have a great demand for active learning and engagement in continuing education. ${ }^{13}$ However, due to remote locations and a lack of educational resources, these nurses have difficulties in accessing face-to face continuing education. ${ }^{14}$ For these nurses, VCPE delivered using the hospital tele-medicine platform is a valuable asset for education.

At county-level medical institutions in China, there is a shortage of clinical pharmacists in the institutions. ${ }^{15}$ Nurses are required to possess certain level of pharmacy knowledge without access to the support of a clinical pharmacist to provide patient care. However, obtaining the continuing education needed requires a significant investment in time and money. The problem is especially severe as the workload of nurses in China is relatively heavy given the population size. ${ }^{16} \mathrm{VCPE}$ allows nurses the flexibility to access learning, ${ }^{12}$ and it is suitable to fit in the Chinese healthcare system. Nurses can choose courses according to their interests and professional needs. At the same time, interprofessional learning can broaden the horizons of nurses and further stimulate their learning interests. ${ }^{17}{ }^{18}$ Suggestions made by the study participants on video recording of lectures and the improvement of teaching styles can further improve the VCPE delivery allowing nurses who cannot participate in the real-time learning to watch the videos at their convenient times.

This study identified several problem areas that deserve improvement. First, lecturers need to appreciate the learning needs of the county nurses and use a style of presentation that actively engages the learners. ${ }^{19}$ The lecturers at higher-level medical institutions are willing to share the latest evidence-based guidelines and diagnosis and treatment standards, which includes how to innovate treatment and nursing care. However, the county-level learners expect that the content of the lectures to be more closely matched to the care demand at the county level. The mismatch of expectations for how to apply the continuing education content and actual content delivery 
discount the education value. ${ }^{20}{ }^{21}$ The current learning atmosphere of VCPE does not engage the participants in the same manner traditional classroom-style learning, which affects learning. Feedback revealed that nurses expect teachers to communicate the learning content with them in advance to help them plan and prepare for lectures. ${ }^{22}$ Nurses would like teachers to interact with them more often and to have their questions answered in real-time. Nurses want teachers to be passionate during lectures to create a good learning atmosphere. ${ }^{23}$

'I don't understand!' and 'How to understand?' are two statements that this research study prioritised in qualitative content analysis. Regarding the issue of 'I don't understand!' the following were commented by participants: (1) Certain content of the course were out of touch with the participants' actual practice. Nurses were looking forward to the content of the course, but sometimes felt that they did not know how to apply the course content to practice. ${ }^{24}$ (2) There were too many abstract pharmaceutical parameters or clinical indicators in lectures. Nursing staff mentioned that they indeed hope to understand the in vivo process of drugs or judge the clinical status of patients through these clinical parameters or indicators. ${ }^{25}$ However, due to differences in professional backgrounds, some specific indicators taught by instructors were difficult to understand by nurses. In addition, the nursing staff said that their English was relatively weak. It was difficult for them to understand specific content with more English terms. ${ }^{26}$ (3) There was too much content in a lecture. Instructors hoped to deliver more content each time, which made it difficult for participants to understand. ${ }^{27}$ () The topics of courses were relatively scattered. Therefore, teaching strategies need to be adapted to the learner and the online learning environment.

Participants made a series of suggestions based on 'how to understand?', including learning content and teaching methods. The nursing staff clearly mentioned that they were looking forward to learning more about adverse drug reactions, and issues related to drug infusion, drug preparation and drug administration, pharmacology, drug storage and medications for special populations. ${ }^{28}$ In addition, they hope that the course content should be based on actual cases with pictures and texts. ${ }^{29}$ Nursing staff conveyed that their teachers should communicate the content in advance to allow them to choose and prepare beforehand. Nursing staff also hope that lecture content can be made into videos for later reviews. 'Passion' and 'interaction' are the main expectations that the nursing staff mentioned to the teachers. Passionate lectures can arouse the enthusiasm of learners, enlighten the atmosphere and make it easier for learners to engage. ${ }^{3031}$ Good classroom interaction can not only promote learners to integrate into the classroom, but also prompt learners to clear their confusions in a timely manner.

This study has the following limitations: (1) The number of subjects was relatively small with participants coming from a single province, Henan, China. However, the study province has a large population and a relatively large number of underserved areas. The province does reflect the development status of China's remote areas. (2) This research only focused on participants' experiences in VCPE and did not explore their experiences in knowledge application to practice and the impact of the application in patients' care. These areas will be studied in the future.

\section{SUMMARY}

Compared with the traditional mode of in-person continuing education, video conferencing pharmacy education delivery to nurses offers convenience, wide accessibility and savings in time and labour. Organisers should carefully plan course content related to nursing practice and engage in interactive teaching styles.

Contributors $\mathrm{ZY}, \mathrm{WZ}$ and $\mathrm{XJ}$ designed the study and conducted the interviews. XY, $Y Z, X i a O Z$ and $P S$ analysed the data. XiangZ and YL wrote the manuscript. XiaojianZ and SD revised the manuscript. $Z Y$ was particularly involved in the drafting, revising of the different versions of the manuscript and final approval of the version to be published. $Z Y$ is responsible for the overall content as the guarantor.

Funding The authors have not declared a specific grant for this research from any funding agency in the public, commercial or not-for-profit sectors.

Competing interests None declared.

Patient and public involvement Patients and/or the public were not involved in the design, or conduct, or reporting, or dissemination plans of this research.

Patient consent for publication Not applicable.

Ethics approval The study was approved by the First Affiliated Hospital of Zhengzhou University Institutional Review Board (No.2019-KY-304). Participants gave informed consent to participate in the study before taking part.

Provenance and peer review Not commissioned; externally peer reviewed.

Data availability statement Data are available on reasonable request. The thematic data that support the findings of this study are available from the corresponding author on reasonable request.

Open access This is an open access article distributed in accordance with the Creative Commons Attribution Non Commercial (CC BY-NC 4.0) license, which permits others to distribute, remix, adapt, build upon this work non-commercially, and license their derivative works on different terms, provided the original work is properly cited, appropriate credit is given, any changes made indicated, and the use is non-commercial. See: http://creativecommons.org/licenses/by-nc/4.0/.

ORCID iD

Zhao Yin http://orcid.org/0000-0003-2589-0962

\section{REFERENCES}

1 Yao D, Xi X, Huang Y, et al. A national survey of clinical pharmacy services in County hospitals in China. PLoS One 2017;12:e0188354.

2 Penm J, Moles R, Wang $\mathrm{H}$, et al. Factors affecting the implementation of clinical pharmacy services in China. Qual Health Res 2014;24:345-56.

3 Li Q, Zhang S-min, Chen H-ting, et al. Awareness and attitudes of healthcare professionals in Wuhan, China to the reporting of adverse drug reactions. Chin Med J 2004;117:856-61.

4 Maidment ID, Damery S, Campbell N, et al. Medication review plus person-centred care: a feasibility study of a pharmacy-health psychology dual intervention to improve care for people living with dementia. BMC Psychiatry 2018;18:340.

5 Ritschl V, Stamm TA, Aletaha D, et al. 2020 EULAR points to consider for the prevention, screening, assessment and management of non-adherence to treatment in people with rheumatic and musculoskeletal diseases for use in clinical practice. Ann Rheum Dis 2020;0:1-7.

6 Thiede E, Miyamoto S. Rural availability of sexual assault nurse examiners (SANEs). J Rural Health 2021;37:81-91. 
7 Joiner-Rogers GL, Delville CL, Timmerman GM. Using videoconferencing for verbal reports to improve clinical nurse specialist student performance. Clin Nurse Spec 2019;33:43-54.

8 Quinlin L, Clark Graham M, Nikolai C, et al. Development and implementation of an e-visit objective structured clinical examination to evaluate student ability to provide care by telehealth. J Am Assoc Nurse Pract 2020;33:359-365

9 Cui F, Ma Q, He X, et al. Implementation and application of telemedicine in China: cross-sectional study. JMIR Mhealth Uhealth 2020;8:e18426.

10 Zhai Y, Gao J, Chen B, et al. Design and application of a telemedicine system jointly driven by videoconferencing and data exchange: practical experience from Henan Province, China. Telemed J E Health 2020;26:89-100.

11 Haase JE. Components of courage in chronically ill adolescents: a phenomenological study. ANS Adv Nurs Sci 1987;9:64-80.

12 Penny RA, Bradford NK, Langbecker D. Registered nurse and midwife experiences of using videoconferencing in practice: a systematic review of qualitative studies. J Clin Nurs 2018;27:e739-52.

13 MacLeod MLP, Stewart NJ, Kosteniuk JG, et al. Rural and remote licensed practical nurses' perceptions of working below their Legislated scope of practice. Nurs Leadersh 2019;32:8-19.

14 Wakerman J, Humphreys J, Russell D, et al. Remote health workforce turnover and retention: what are the policy and practice priorities? Hum Resour Health 2019;17:99.

15 Fang Y, Yang S, Zhou S, et al. Community pharmacy practice in China: past, present and future. Int J Clin Pharm 2013;35:520-8.

16 Bei-Lei L, Yong-Xia M, Fa-Yang M, et al. Current status and nurses' perceptions of the electronic tabular nursing records in Henan, China. J Nurs Manag 2019;27:616-24.

17 Collins A, Broeseker A, Cunningham J, et al. A longitudinal online interprofessional education experience involving family nurse practitioner students and pharmacy students. J Interprof Care 2017;31:218-25.

18 Moote R, Claiborne M, Galloway A. Interprofessional education telephone simulation for campus-based pharmacy students and distance-learning family nurse practitioner students. Curr Pharm Teach Learn 2019;11:264-9.
19 Dobbin KR. Applying learning theories to develop teaching strategies for the critical care nurse. Don't limit yourself to the formal classroom lecture. Crit Care Nurs Clin North Am 2001;13:1-11.

20 Corlett J. The perceptions of nurse teachers, student nurses and preceptors of the theory-practice gap in nurse education. Nurse Educ Today 2000;20:499-505.

21 Tang FWK, Chan AWK. Learning experience of nursing students in a clinical partnership model: an exploratory qualitative analysis. Nurse Educ Today 2019;75:6-12.

22 Hsu L-L. An analysis of clinical teacher behaviour in a nursing practicum in Taiwan. J Clin Nurs 2006;15:619-28.

23 Ackerman-Barger K, Dickinson JK, Martin LD. Promoting a culture of Civility in nursing learning environments. Nurse Educ 2021;46:234-8.

24 Dyer JM, Latendresse G. Identifying and addressing problems for student progression in midwifery clinical education. J Midwifery Womens Health 2016;61:28-36.

25 Foster J, Flanders S. Challenges in clinical nurse specialist education and practice. Online J Issues Nurs 2014;19:1.

26 Wilbur K, Kelly I. Interprofessional impressions among nursing and pharmacy students: a qualitative study to inform interprofessional education initiatives. BMC Med Educ 2015;15:53.

27 MacKinnon K, Marcellus L, Rivers J, et al. Student and educator experiences of maternal-child simulation-based learning: a systematic review of qualitative evidence protocol. JBI Database System Rev Implement Rep 2015;13:14-26.

28 Bell HT, Granas AG, Enmarker I, et al. Nurses' and pharmacists learning experiences from participating in interprofessional medication reviews for elderly in primary health care - a qualitative study. BMC Fam Pract 2017;18:30.

29 Forsberg E, Ziegert K, Hult H, et al. Assessing progression of clinical Reasoning through virtual patients: an exploratory study. Nurse Educ Pract 2016;16:97-103.

30 Ashworth L. Challenges and opportunities: the role of the district nurse in influencing practice education. $\mathrm{Br} J$ Community Nurs 2020;25:402-6.

31 Carr G. Changes in nurse education: being a nurse teacher. Nurse Educ Today 2007;27:893-9. 